\title{
Influence of thermo mechanical pre-treatment on efficiency and temperature stability of shape memory alloys
}

\author{
S. Langbein ${ }^{\mathrm{a}}$ and K. Lygin \\ Ruhr-University Bochum, Institute of Engineering Design, 44780 Bochum, Germany
}

\begin{abstract}
The functional "programming" of one SMA-component is of substantial interest in the case of actuator applications regarding standardisation of components and integration of component parts. For the programming of components it is necessary to make a thermo mechanical pre-treatment. This treatment influences not only the effect characteristic and the transformation temperatures, but also characteristics such as the efficiency and temperature stability.

In order to study the influence of the thermo mechanical pre-treatment on the efficiency and temperature stability, wires of high-nickel pseudo elastic and low-nickel pseudo plastic alloys under change of various parameters were functionally characterised in the present study. In this context, tension tests and temperature-controlled heating tests were carried out. A test stand was developed especially for the heating tests. The heating tests were implemented to determine the one-way effect properties, such as the transformation temperatures, hysteresis, the irreversible strains etc. and also to determine the short-time and permanent temperature stabilities. In addition, the tests were carried out with different loads. Particularly the high-nickel alloys showed a very large potential. Among the well-known pseudo elastic applications by defined pre-treatment they can also be used as actuators.
\end{abstract}

\section{Introduction}

Shape Memory Alloys (SMA) have essential advantages in comparison with conventional actuators, in particular the high power density and the silent mode of operation. However, this material has not gained acceptance in technical applications yet. The main reasons are the missing simulation tools and a lack of knowledge of materials as well as the companies' uncertainty to handle the SMA's.

Therefore, this article investigates the impact of thermo mechanical pre-treatment on the characteristics of lownickel and high-nickel alloys. In this context, configured samples are evaluated with regards to selected parameters of efficiency. Furthermore, the function stability of samples with a high efficiency under the influence of temperature is analysed.

\section{Experimental Procedure}

The experimental analysis can be divided into sections such as thermo mechanical configuration, pull-out test, activation and temperature stability analysis.

The tests analyse the characteristics of SM-wires made of low-nickel and high-nickel alloys, with a diameter between $0.2 \mathrm{~mm}$ and $0.4 \mathrm{~mm}$. Under the influence of room temperature the high-nickel alloy shows pseudo elastic behaviour while the low-nickel alloy shows a thermal effect.

Table 1 shows the essential characteristics of both alloys.

Table 1: Characteristics of samples

\begin{tabular}{|c|c|c|c|c|c|}
\hline alloy & Ni [at\%] & Ti [at\%] & $\mathbf{A}_{\mathbf{f}}\left[{ }^{\circ} \mathbf{C}\right]$ & Density $\left[\mathbf{k g} / \mathbf{m}^{\mathbf{3}}\right]$ & SM-Effect \\
\hline $\mathbf{H}$ & 54.79 & 45.07 & 95 & 6410 & thermal \\
\hline $\mathbf{S}$ & 55.91 & 43.95 & 0 & 6490 & pseudoelastic \\
\hline
\end{tabular}

\footnotetext{
a e-mail: langbein@lmk.rub.de
}

This is an Open Access article distributed under the terms of the Creative Commons Attribution-Noncommercial License (http://creativecommons.org/licenses/by-nc/3.0/), which permits unrestricted use, distribution, and reproduction in any noncommercial medium, provided the original work is properly cited. 


\subsection{Thermo mechanical pre-treatment}

The modification of specific characteristics of the low-nickel and high-nickel SM-wires is caused by thermo mechanical pre-treatment. This treatment includes the annealing of cold drawn wire samples in an oven (deformation approx. 30\%), under variation of the parameters annealing temperature and annealing time. According to [1], the annealing of the wire samples takes place in the region between $300^{\circ} \mathrm{C}$ and $700^{\circ} \mathrm{C}$. The annealing times were 5 and 20 minutes respectively. The configuration parameters of the analyzed wire samples are listed in Table 2.

Table 2: Parameters of thermo mechanical pre-treatment

\begin{tabular}{|c|c|c|}
\hline alloy & annealing temperature $\left[{ }^{\circ} \mathbf{C}\right]$ & annealing time [min] \\
\hline $\mathbf{H}$ & $300,400,500,600,700$ & 5,20 \\
\hline $\mathbf{S}$ & $300,400,500,600,700$ & 5,20 \\
\hline
\end{tabular}

\subsection{Pull-out test}

The thermo mechanical pre-treated SMA-wires undergo the pull-out test in order to determine the relevant functional characteristics of the samples. At first the test determines which SM-effect is caused by the thermo mechanical pre-treatment. In samples of the high-nickel alloy $\mathrm{S}$ the pseudo elastic effect as well as the thermal effect can occur, for example. Additionally, this analysis determines the rate of the martensitic and/or austenitic plateau stress and the residual strain of the wire samples. Fig. 1(a) depicts pull-out test stand used for the test analysis.

\subsection{Activation test}

Activation of the SM-wires follows the pull-out test. The activation is carried out in a specially-developed test stand. This test detects the transformation temperatures as well as the variation of the pseudo plastic strain, which are an indicator for the performance of the thermal effect.

Fig. 1(b) shows the activation test stand.

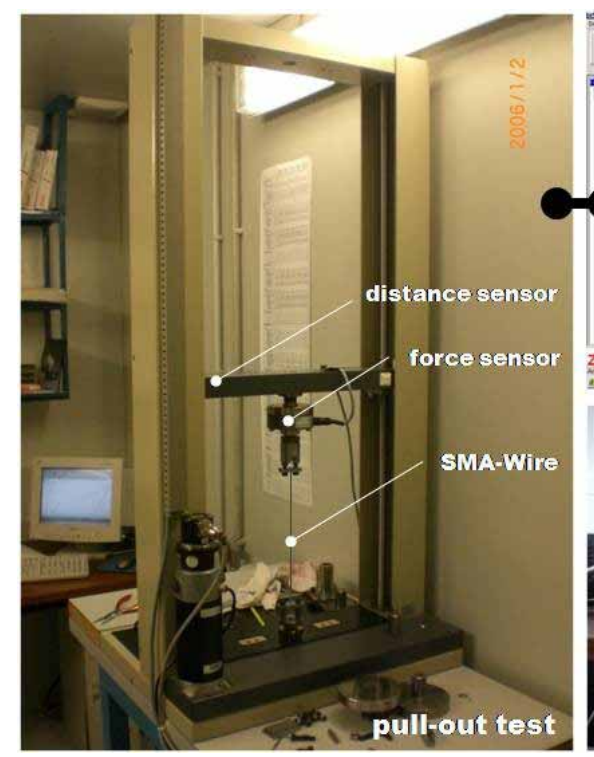

a)

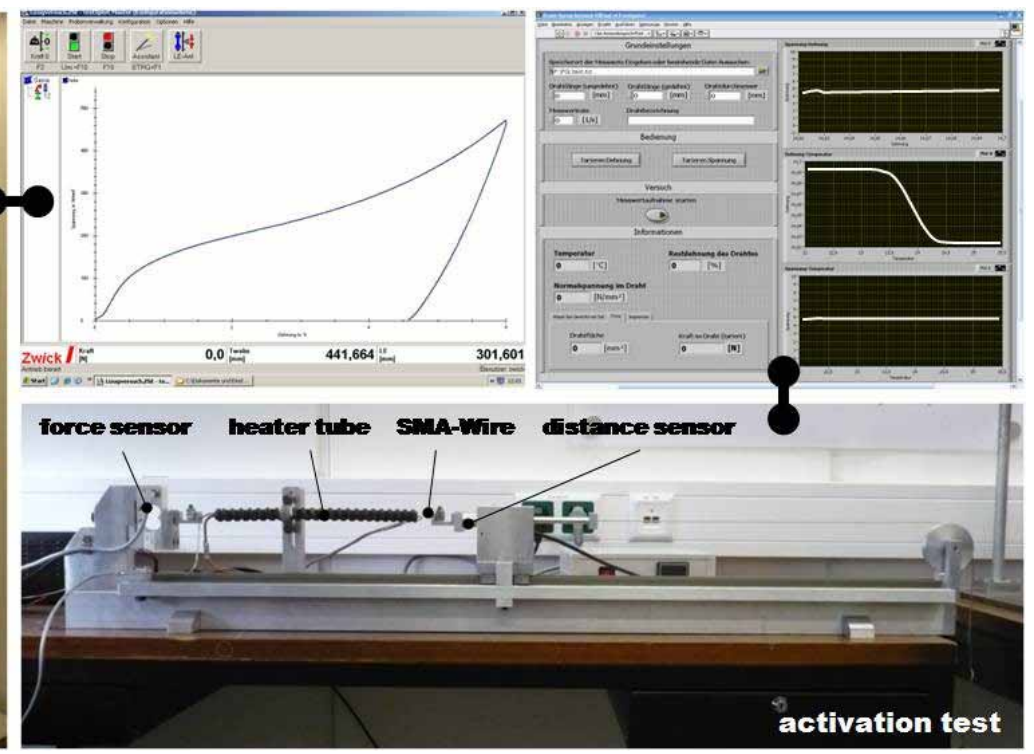

b)

Fig. 1: pull-out test (a) and activation test stand (b)

\subsection{Temperature stability test}

The temperature stability test analyses the impact of the thermo mechanical pre-treatment of the SM-wires on the stability of the SM-effect under the influence of increased temperatures. The test can be divided into a series of experiments, e.g. short-time strength and fatigue-strength analysis. In terms of the short-time strength tests a 
strained and loaded wire is continuously heated to high temperatures until it loses the SM-effect and expands. The pre-strain and the load represent the variable test parameters. The analysis of the fatigue-strength observes the impact of a permanent prevailing temperature on the stability of the SM-effect. In this case the configured wire is pre-strained to a defined value, applied with a certain load and maintained at a constant temperature for several days. The elongation of the wire indicates its efficiency loss. Both temperature stability tests are carried out in the activation test stand (cf. Fig. 1(b)).

\section{Results and Discussion}

\subsection{Pull-out test}

All thermo mechanical configured samples undergo the pull-out test in order to specify their characteristics such as type of effect, plateau level and residual strain. The samples are strained to $6 \%$. This strain value is selected because at this particular strain it is still part of the region of the martensitic stress plateau.

Fig. 2 shows the results of the pull-out test of the S alloy samples. Only because of this high-nickel alloy there is the possibility to achieve the coexistence of the thermal and the pseudo elastic effect. This is done by shifting the transformation temperatures from generally $0^{\circ} \mathrm{C}\left(\mathrm{A}_{\mathrm{f}}\right.$-Temperatures $)$ to $30^{\circ} \mathrm{C}$ or $40^{\circ} \mathrm{C}$. Inner stress areas are responsible for the shift of transformation temperatures which are caused by dislocation or precipitation particles [2].

Fig. 2 on the right depicts:

- That a substantial pseudo elastic characteristic only occurs with the 300-5er and the 500-5er samples.

- All samples of the high-nickel alloy $\mathrm{S}$ have a substantial stress plateau of different values depending on the configuration temperature.

- The lowest plateau stress (approx. $350 \mathrm{~N} / \mathrm{mm}^{2}$ ) and the highest residual strain occur at the 500-20er sample.

- The plateau form slightly increases in all samples except for the 700er sample.

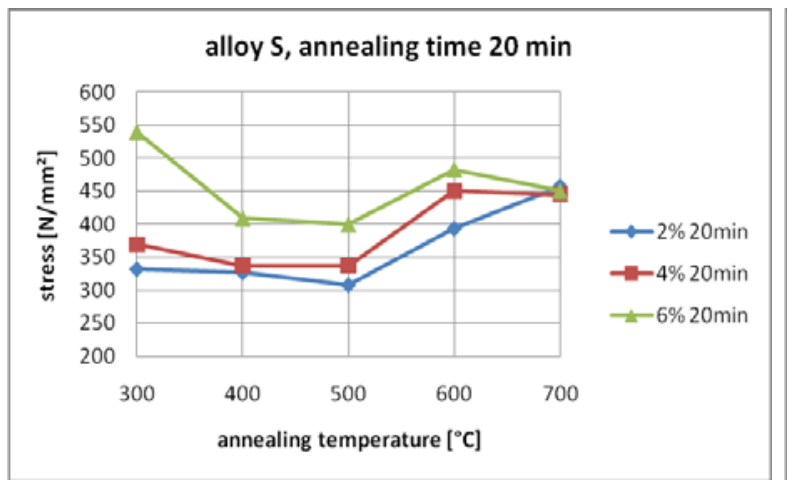

a)

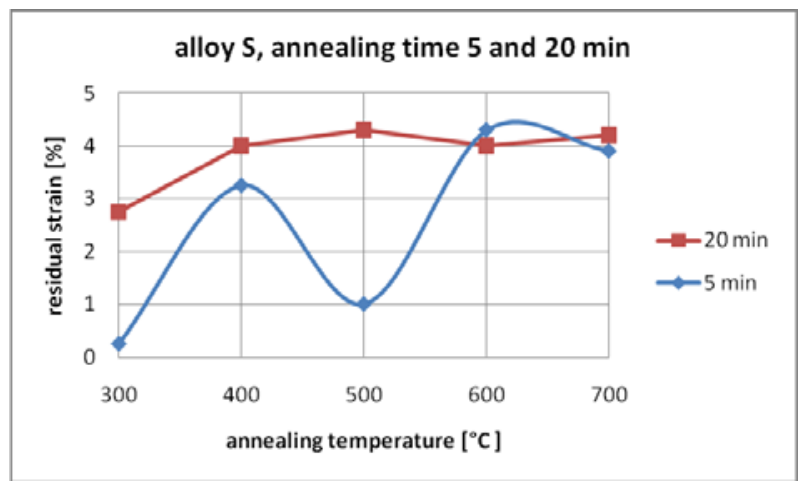

b)

Fig. 2: Distribution of stress of the 20 min annealed samples (a) and residual strains of all samples with high-nickel alloys (b).

Fig. 3 shows the results of the tensile test of the low-nickel alloy samples $H$. The general results are:

- All samples of this alloy show that the thermal effect is not dependent on annealing time

- The different mechanical characteristics regarding annealing temperature can be traced back to the recovery and re-crystallization processes within the atomic structure of these samples.

- During the strain process, all samples of the low-nickel alloy $\mathrm{H}$ achieve the martensitic stress plateau after an elastic region (up to 1\% strain), which is typical for SMA's. The stress level is not even half as much as the level of the S-samples.

- The lowest plateau stress (approx. $150 \mathrm{~N} / \mathrm{mm}^{2}$ ) and the highest residual strain can be detected for the 500-20er sample. According to [1], this behavior can be explained by a distinctive sub-grain structure, which is common for these annealing parameters. 


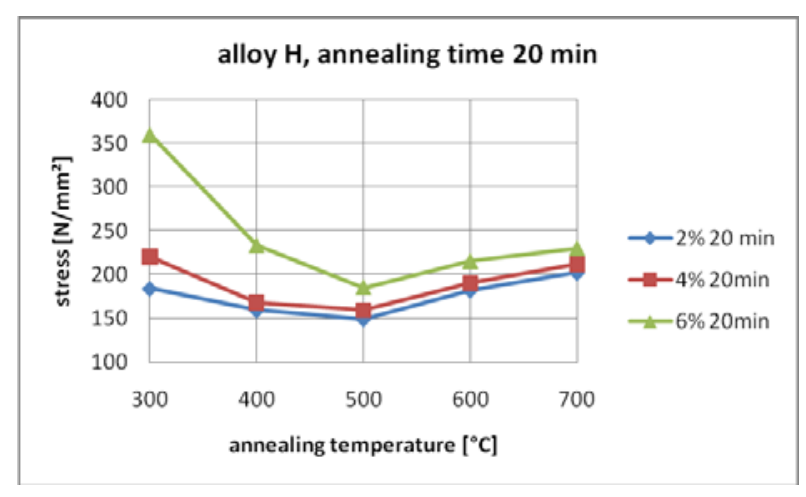

a)

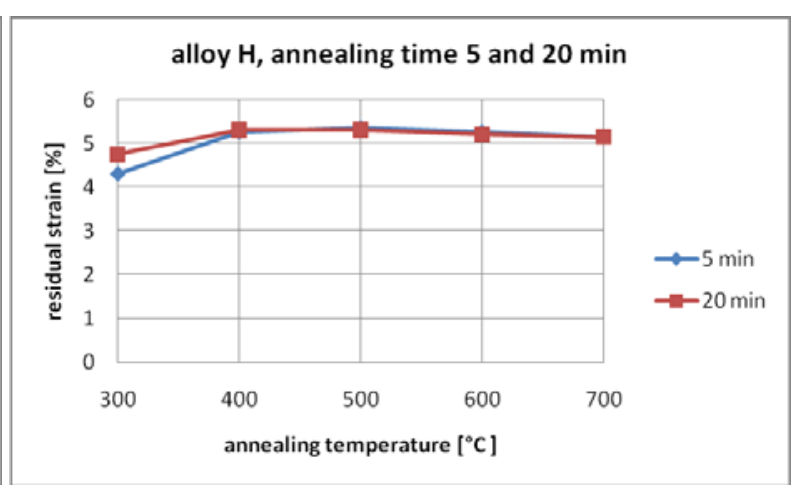

b)

Fig. 3: Distribution of stress of the 20 min annealed samples (a) and residual strains of all samples with low-nickel alloys (b).

\subsection{Activation test}

Evaluation of the activation test results are carried out in standard strain-temperature diagrams. Specific values such as the transformation temperatures or the irreversible strains of the samples can be taken from these diagrams (cf. Figs 4 and 5). Some samples of the alloy S show a lower residual strain before the activation than after the straining process. This conclusion is based on the fact that the samples already undergo parts of the austenitic phase change at room temperature due to their low $\mathrm{A}_{\mathrm{s}}$-Temperatures. Consequently, the strain of the wire resulting from the pull-out test is reduced. The following results can be taken from the diagrams:

- The 400-20er and the 500-20er samples show the best one-way behaviour of all tested samples of the alloy $\mathrm{S}$ with a high residual strain before activation of approx. $4 \%$ and a minimal residual strain after activation.

- The temperature region of the austenitic phase change however shows higher values of approx. $30^{\circ} \mathrm{C}$ for the 500-20er sample. This trend continues with further increase of the annealing temperature. It is likely that the partial interference of the transformation fronts caused by growing precipitation particles is responsible for this trend.

- Regarding transformation temperatures it can be seen that only the $\mathrm{A}_{\mathrm{f}}$-Temperatures vary in accordance with the configuration parameters. The $\mathrm{A}_{\mathrm{s}}$-Temperatures remain almost constant.

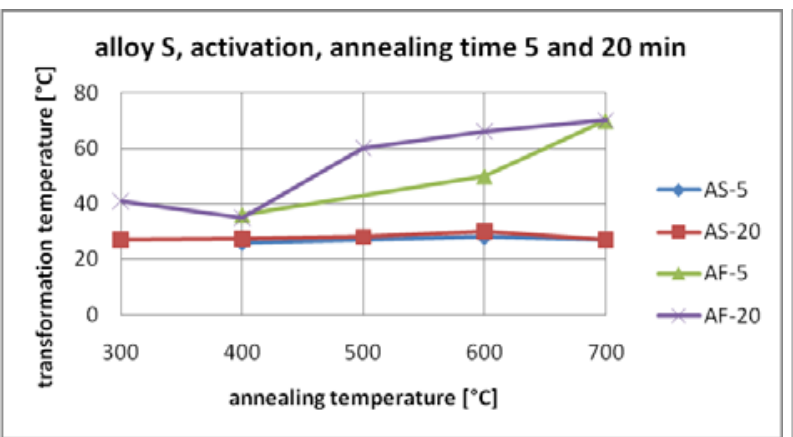

a)

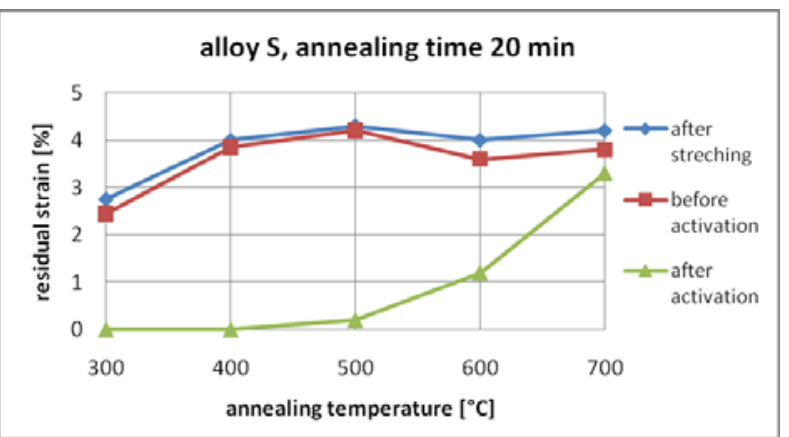

b)

Fig. 4: Transformation temperatures (a) and residual deformation (b) of the S-samples.

Fig. 5 shows the results for the H alloys and leads to the following conclusions:

- The austenitic transformation of the H-alloy samples proceeds in accordance with the annealing parameters. In contrast to the S-alloys they also have considerably different temperatures. (cf. Fig. 5 (a)).

- The 300er sample shows the best functional characteristics; its dislocation structure still remains. Before activation the residual strain is approx. 5\%; after activation it runs toward $1 \%$.

- The transformation of the $300-20 \mathrm{er}$ sample starts at $50^{\circ} \mathrm{C}$. This is unusual as the alloy $\mathrm{H}_{\text {has }} \mathrm{A}_{\mathrm{s}}$ temperature of $85^{\circ} \mathrm{C}$ according to manufacturer data. This can be explained by an increased transformation disposition of the strongly deformed structure. 
- The 400-20er sample already has a transformation temperature of $110^{\circ} \mathrm{C}$. Starting with the 500er sample the graphs differ only insignificantly. The start of transformation is $120^{\circ} \mathrm{C}$ for all samples.

- In contrast to the alloy $\mathrm{S}$ the transformation interval does not show any considerable variation while increasing the annealing temperature [3].

- Concerning residual deformation it can be stated that with increased transformation temperatures and transformation times the irreversible deformation after activation also increases. This leads to a reduction of the effect value.

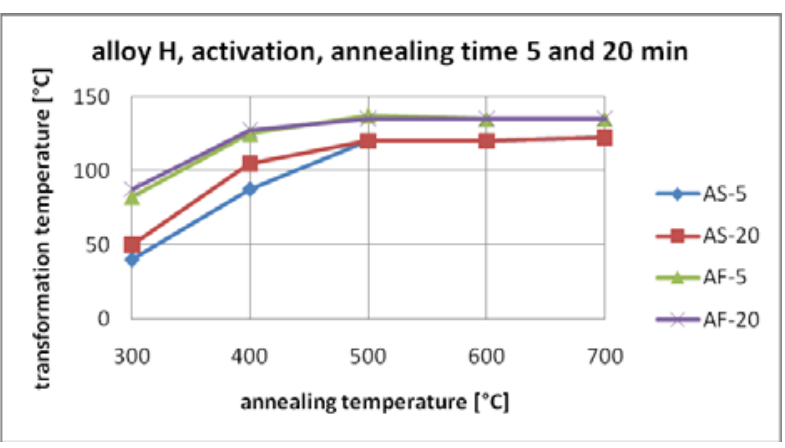

a)

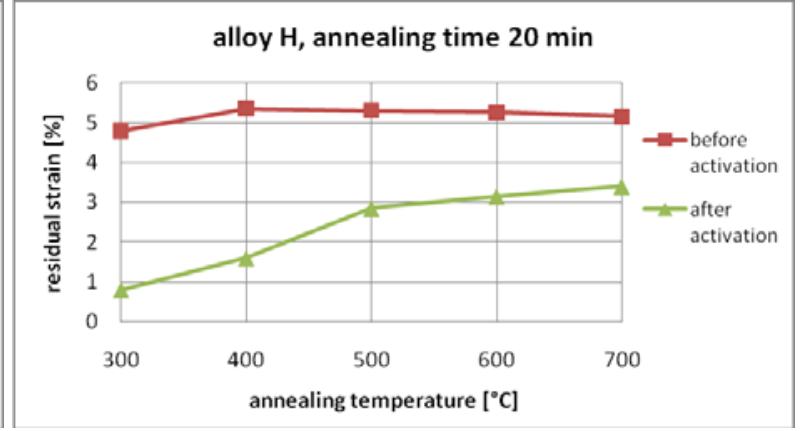

b)

Fig. 5: Transformation temperatures (a) and residual deformation (b) of the H-samples.

\subsection{Temperature stability}

The SM-wires of the high-nickel alloy S show a distinctive thermal effect at annealing temperatures of $400^{\circ} \mathrm{C}$ and $500^{\circ} \mathrm{C}$ combined with an annealing time of 20 minutes. Therefore, the temperature stability of these samples is analysed. Moreover, the austenitic phase change can be monitored with conventional test methods in the activation test stand.

The samples of the low-nickel alloy H only show a one-way effect. However, many of the tested samples have similar characteristics regarding their transformation temperatures and plateau level. This is why the tests only cover samples which have the largest margins with regards to their characteristics. These samples are the SMwires, which were annealed for 20 minutes at temperatures of $300^{\circ} \mathrm{C}$ and $500^{\circ} \mathrm{C}$.

\subsubsection{Short-term stability}

For the investigation of the short-term stability, the samples of both alloys are charged with different loads and are pre-strained with different strengths.

Table 3 indicates the test parameters of the short-term stability tests.

Table 3: Parameters of the short term stability test

\begin{tabular}{|c|c|c|c|c|}
\hline alloy & annealing temperature $\left[{ }^{\circ} \mathbf{C}\right]$ & annealing time [min] & strain [\%] & pre-stressing [N/ $\mathbf{m m}^{\mathbf{}}$ ] \\
\hline $\mathbf{S}$ & 400,500 & 20 & $2,4,6$ & $100,200,400$ \\
\hline $\mathbf{H}$ & 300,500 & 20 & $2,4,6$ & $100,200,400$ \\
\hline
\end{tabular}

Determination of the breakdown temperature of SM-elements results by means of stress-temperature-diagrams (cf. Fig. 6). These breakdown temperatures only account for very short dwelling times in a single digit minute value. If the dwelling time required to reach the temperature stability is increased, the breakdown temperature will be reduced significantly. This is also illustrated by the results of the long-term tests.

The diagram allows the following conclusions with regards to the impact of the pre-stress and pre-strain as well as the pre-treatment.

- The pre-stress has a significant impact on the breakdown temperature. Especially the step from 100 to $200 \mathrm{~N} / \mathrm{mm}^{2}$ is notable. Here the breakdown temperature for all samples is reduced by approx. $50^{\circ} \mathrm{C}$. From $200 \mathrm{~N} / \mathrm{mm}^{2}$ the reduction of the breakdown temperature is less intense. This fact indicates that, from a critical stress of $200 \mathrm{~N} / \mathrm{mm}^{2}$ onwards, re-crystallization processes already take place at lower temperatures.

- The pre-strain plays only a secondary role, or it has no impact at all on the breakdown temperature. 
- In comparison to the pre-strain, the configuration parameters and/or the type of alloy show a significant impact on the breakdown temperature. In this context the S-alloy performs better than the H-alloy. The breakdown temperatures of the S-samples are approx. $75^{\circ} \mathrm{C}$ higher for the $400 \mathrm{er}$ and approx. $100^{\circ} \mathrm{C}$ higher for the 500er samples. A reason for this could be the existence of precipitation particles inside the high-nickel S-alloy. These interfere with re-crystallization, or they need more energy to dissipate, which leads to higher breakdown temperatures.

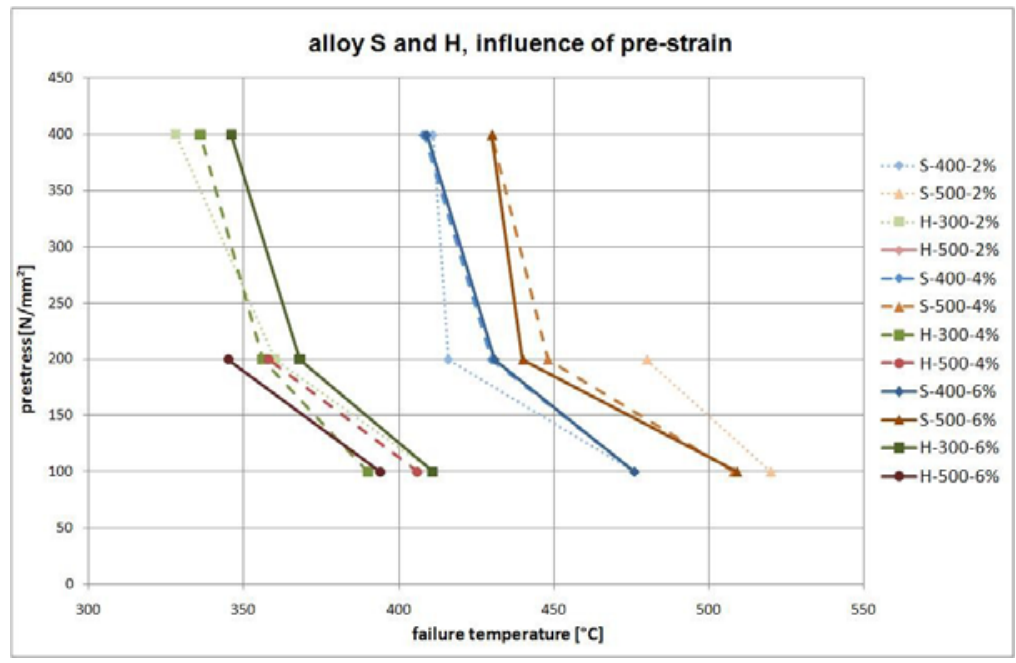

Fig. 6: Breakdown temperature in relation to pre-stress for different pre-treatments.

\subsubsection{Fatigue strength}

The fatigue strength analysis is performed for samples of both alloys, which are annealed for 20 minutes at temperatures of $500^{\circ} \mathrm{C}$. Fig. 7 shows these selected samples, charged with different loads. The results are:

- A smaller load of $20 \mathrm{~N} / \mathrm{mm}^{2}$ in an investigation time period of 10 days; at temperatures of $450^{\circ} \mathrm{C}$ (alloy $\mathrm{S})$ and $400^{\circ} \mathrm{C}$ (alloy $\mathrm{H}$ ) there is no considerable decline of the SM-effect.

- A doubling of the load to $40 \mathrm{~N} / \mathrm{mm}^{2}$ for the sample of alloy $\mathrm{S}$ results in a significant strain of the wire and therefore in a reduced fatigue strength.

- The impact of the stress is not that serious for the H-alloy. A considerable stability loss of the wire can only be observed at a pre-stress of $80 \mathrm{~N} / \mathrm{mm}^{2}$.

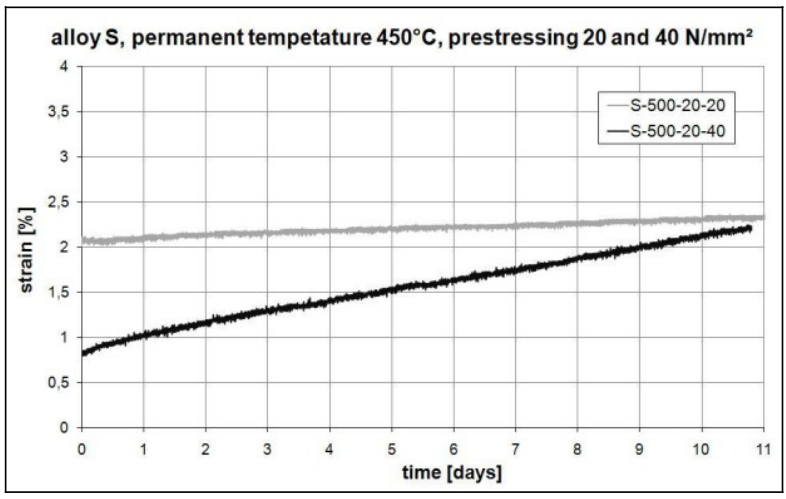

a)

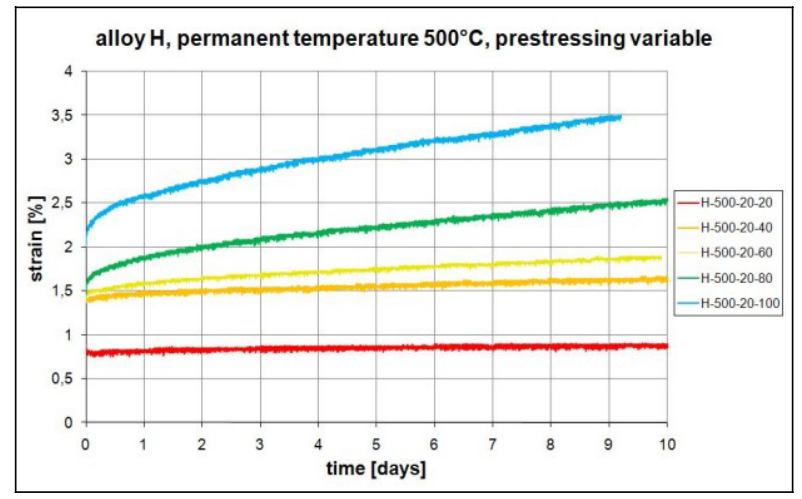

b)

Fig. 7: Fatigue strength of a high-nickel sample of alloy S (a), fatigue strength of a low-nickel sample of alloy H (b)

Fig. 8(a) depicts the samples of the alloys $\mathrm{S}$ and $\mathrm{H}$, which show the same configuration and pre-stress. In these samples only the test temperature varies. It can be concluded that:

- The increase of $25^{\circ} \mathrm{C}$ of the test temperature for the alloy $\mathrm{S}$ and the increase of $50^{\circ} \mathrm{C}$ for the alloy $\mathrm{H}$ leads to a significant decline in the long-term characteristics. Furthermore, the alloy $\mathrm{S}$ shows a better stability behavior again. 
Fig. 8(b) depicts a comparison of two samples of the alloys $\mathrm{H}$ and $\mathrm{S}$. They have the same configuration but they are charged with different pre-stresses and heated with different test temperatures. The alloy $\mathrm{H}$ shows:

- The sample with the higher pre-stress shows a higher residual strain of approx. $2 \%$.

- The two graphs have identical curves. Therefore, one can assume that the fatigue strength characteristics of NiTi-wires can be changed by parameters such as pre-stress and ambient temperature [4].

- As a result, a higher fatigue strength can be caused by reducing the pre-stress or lowering the ambient temperature.

- The same applies for the test graphs of alloy $\mathrm{S}$.

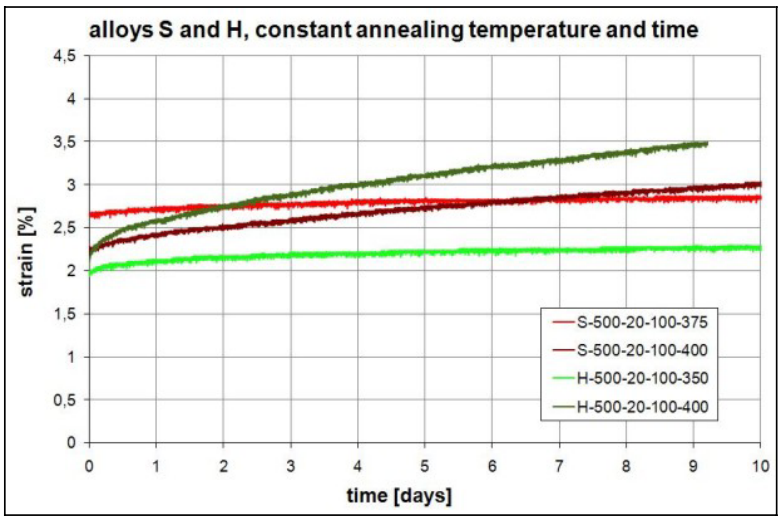

a)

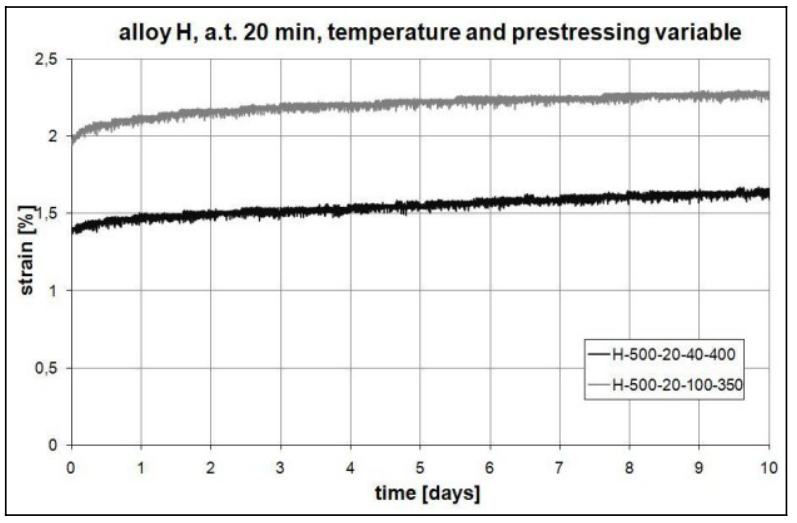

b)

Fig. 8: Comparison of fatigue strength; variation of parameters test temperature (a), and test temperature and pre-stress (b)

\section{Conclusions}

The effect size of the SM-wires decreases in all experiments if the configuration temperature is increased. The best results regarding the characteristics of the thermal effect show the samples of the high-nickel alloy $\mathrm{S}$ at a configured temperature of $400^{\circ} \mathrm{C}$ and $500^{\circ} \mathrm{C}$ and a configured period of 20 minutes. Samples with adequate treatment have a well-developed parameter "technical utilizable effect-value" which shows a value of $4 \%$ with the wire' pre-strain of $6 \%$. The parameter itself results from the difference of the residual strains after the pullout test and after activation.

The samples of low-nickel alloy $\mathrm{H}$ perform best at a configuration temperature of $300^{\circ} \mathrm{C}$. At this temperature the technically usable effect value lies at $4 \%$, while pre-straining the wire to $6 \%$. Further configuration parameters are also available for alloy $\mathrm{H}$ and these led to similar effect values.

While performing the temperature stability tests, it could be observed that an increased pre-strain of the SM-wire had no considerable impact on the short-term stability of the samples. However, the increase of the pre-strain of the wire samples led to a significant decrease of the breakdown temperature of the SM-wire. While performing the fatigue strength tests, the impact of the pre-stress on the stability of the samples was investigated and verified. Already low pre-stresses of $20 \mathrm{~N} / \mathrm{mm}^{2}$ led to a decline of the stability characteristics, which were shown by the elongation of the SM-wires. Furthermore, the impact of the temperature on the fatigue strength was investigated. The results lead to the conclusion that an increase of the ambient temperature is equivalent to the pre-stress of a lower temperature durability of the SM-wires.

\section{Acknowledgement}

The authors acknowledge funding by the Deutsche Forschungsgemeinschaft (DFG) within the framework of the project B1 of SFB 459 (Sonderforschungsbereich: Formgedächtnistechnik).

\section{References}

[1] D. Treppmann, Thermomechanische Behandlung von NiTi. (VDI Verlag GmbH, Düsseldorf, 1997)

[2] D. Stöckel, Engineering Aspects of Shape Memory Alloys. (Butterworth-Heinemann Ltd, London, 1990)

[3] E.G. Welp; S. Langbein, Survey of the in-situ configuration of cold-rolled, nickel rich NiTi sheets to create variable component functions. (Elsevier Science, Material Science and Engineering, 2007)

[4] A. Heckmann, Mikrostruktur und Ermüdung von NiTi-Formgedächtnislegierungen. (VDI Verlag GmbH, Düsseldorf 2003) 